\title{
Novel Electrically Small Spherical Electric Dipole Antenna
}

\section{Kim, Oleksiy S.}

Published in:

iWAT

Link to article, DOI:

10.1109/IWAT.2010.5464850

Publication date:

2010

Document Version

Publisher's PDF, also known as Version of record

Link back to DTU Orbit

Citation (APA):

Kim, O. S. (2010). Novel Electrically Small Spherical Electric Dipole Antenna. In iWAT IEEE Computer Society Press. https://doi.org/10.1109/IWAT.2010.5464850

\section{General rights}

Copyright and moral rights for the publications made accessible in the public portal are retained by the authors and/or other copyright owners and it is a condition of accessing publications that users recognise and abide by the legal requirements associated with these rights.

- Users may download and print one copy of any publication from the public portal for the purpose of private study or research.

- You may not further distribute the material or use it for any profit-making activity or commercial gain

- You may freely distribute the URL identifying the publication in the public portal

If you believe that this document breaches copyright please contact us providing details, and we will remove access to the work immediately and investigate your claim 


\title{
Novel Electrically Small Spherical Electric Dipole Antenna
}

\author{
Oleksiy S. Kim \\ Department of Electrical Engineering, Technical University of Denmark \\ Ørsteds Plads, Building 348, DK-2800, Kgs.Lyngby, Denmark \\ Email: osk@elektro.dtu.dk
}

\begin{abstract}
This paper indroduces a novel electrically small spherical meander antenna. Horizontal sections of the meander are composed of wire loops, radii of which are chosen so that the whole structure is conformal to a sphere of radius $a$. To form the meander the loops are connected by wires at a meridian plane. The antenna operates as an electric dipole, i.e. it radiates the $\mathrm{TM}_{10}$ spherical mode. The antenna is self-resonant and can be matched to a wide range of input feed lines without an external matching network. In this paper, a spherical meander antenna of the size $k a=0.27$ and the input impedance of $72 \mathrm{ohms}$ is numerically investigated and its performance is compared to that of the multiarm spherical helix antenna of the same size. Both antennas yield equal quality factors, which are about 1.5 times the Chu lower bound, but quite different cross-polarization characteristics.
\end{abstract}

\section{INTRODUCTION}

In the last two decades we have witnesses a tremendous growth of wireless communication systems and services. This process attended with continuing miniaturization of portable communication devices necessitates the development of physically small antennas, which in many cases means electrically small. Since early works by Wheeler [1] and Chu [2], it has been known that the electrical performance of electrically small antennas (ESA) is subject to certain limitations. The minimum radiation quality factor of an electrically small dipole antenna inscribed in a sphere of radius $a$ can be expressed as [3]

$$
Q_{\mathrm{LB}}=\frac{1}{(k a)^{3}}+\frac{1}{k a},
$$

where $k$ is the free space propagation constant. This ultimate lower bound, sometimes referenced as the Chu lower bound, is obtained under an assumption that there is no stored electric energy for an electric dipole antenna (magnetic energy for a magentic dipole antenna) inside the minimum sphere of radius $a$. Less conservative bounds derived by Thal [4] for source currents located on the surface of the minimum sphere account for the corresponding stored energies inside that sphere. For electric and magnetic ESA these bound are $Q \rightarrow 1.5 Q_{\mathrm{LB}}$ and $Q=3.0 Q_{\mathrm{LB}}$, as $k a \rightarrow 0$, respectively. Multiarm spherical helix wire [5] and slot [6] antennas are examples of electrically small electric and magnetic dipole antennas, respectively, that approach the Thal bounds. Recently, three novel electrically small magnetic dipole antennas with $Q \rightarrow 3.0 Q_{\mathrm{LB}}$ were presented in [7].

In this paper, a novel electrically small electric dipole antenna is introduced. The antenna is a self-resonant spherical meander radiating the $\mathrm{TM}_{10}$ spherical mode. The radiation quality factor of this antenna approaches the bound $1.5 Q_{\mathrm{LB}}$. A comparison is made to another electrically small electric dipole antenna - the multiarm spherical helix [8]. Numerical result presented here are obtained with the surface integral equation technique [9] assuming perfectly electrically conducting wires and a delta gap voltage generator.

\section{SPHERICAL MEANDER ANTENNA}

As sketched in Fig 1, wire loops are equidistantly arranged in $\theta$ over the antenna spherical surface. With wires connecting the loops in the XZ-plane, the whole structure becomes a meander, which is particularly evident from the side view of the antenna in Fig. 2. Obviously, for an electrically small antenna horizontal meander sections formed by the wire loops contribute weakly to the antenna far fields due to the symmetry and oppositely directed currents. However, although the main radiation is due to the vertical wires, the loops play an important role in reducing the antenna resonance frequency. Consider the spherical meander antenna with radius

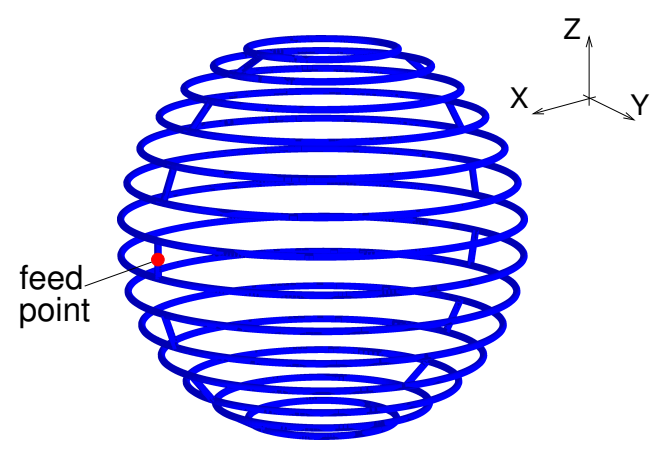

Fig. 1. Spherical meander antenna. 


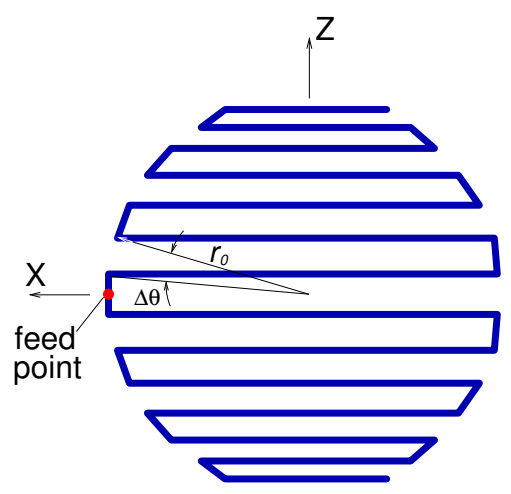

Fig. 2. Side view of the spherical meander antenna.

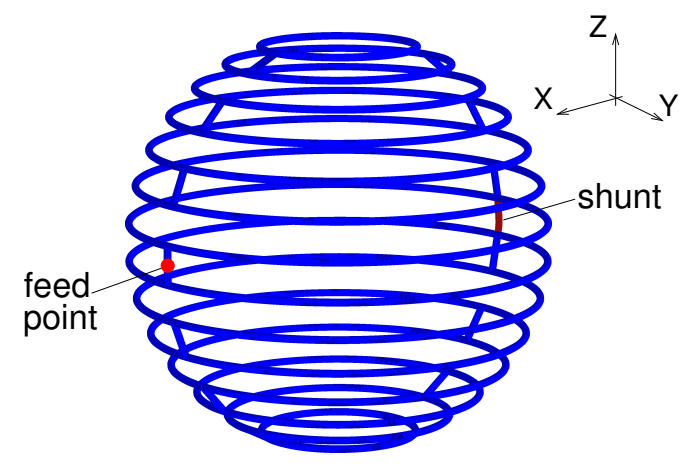

Fig. 3. The shunt-matched spherical meander antenna.
Tab. 1. Characteristics of the spherical meander antenna.

\begin{tabular}{ccccc}
\hline \hline Number of loops & $\Delta \theta$ & $f_{0}, \mathrm{MHz}$ & $R_{0}, \Omega$ & $Q / Q_{\mathrm{LB}}$ \\
\hline \hline 0 & - & 1058 & 48.5 & 3.11 \\
6 & 30.0 & 357.5 & 2.8 & 2.04 \\
10 & 17.6 & 300.2 & 1.9 & 1.81 \\
16 & 10.5 & 269.5 & 1.5 & 1.71 \\
\hline 14 (flat) & 10.5 & 373.5 & 2.9 & 3.66 \\
\hline 16 + shunt & 10.5 & 300.4 & 71.8 & 1.68 \\
\hline \hline
\end{tabular}

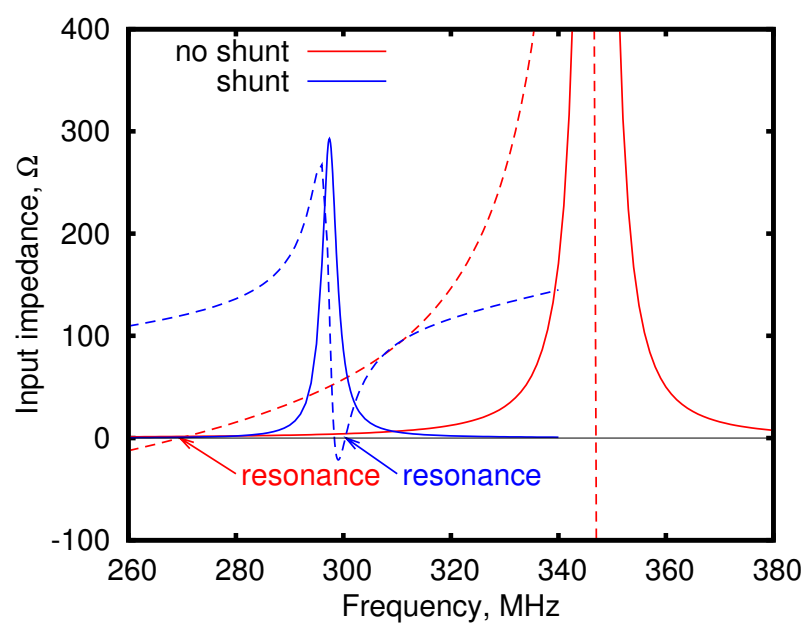

Fig. 4. Input impedance of the spherical meander antenna with and without shunt.

$r_{0}=42.2 \mathrm{~mm}$ made of wire $2 r_{w}=2.6 \mathrm{~mm}$ in diameter. The antenna radius $r_{0}$ is measured from the origin to the wire axes, and thus, the antenna occupies a spherical volume of radius $a=r_{0}+r_{w}=43.5 \mathrm{~mm}$. Tab. 1 summarizes the resonance frequency $f_{0}$, the resonance input resistance $R_{0}$, and the ratio $Q / Q_{\mathrm{LB}}$ of the antenna for various values of $\Delta \theta$. It is observed that the resonance frequency reduces almost by factor of four as the number of loops increases from 0 (simple curved dipole) to 16 , although the total length of the vertical wire sections remains approximately the same. Moreover, the ratio $Q / Q_{\mathrm{LB}}$ drops from 3.11 to 1.71 . The spherical meander antenna also shows favorable performance characteristics as compared to a flat meander antenna, whose cross section coincides with the side view in Fig. 2. Thus, parasitic capacitors formed by the horizontal loops not only make the spherical meander antenna electrically small, but also reduce the relative part of the reactive energy stored inside the spherical antenna volume.

The only problem, however, is that the input resistance at the resonance drops to unacceptably small values. By applying a shunt wire as shown in Fig. 3, the input resistance is raised to 72 ohms (Tab. 1). The input impedance behavior versus frequency changes from the dipole-like to loop-like, that is the antiresonance occurs first (Fig. 4). The shunt can be applied not only at the position opposite to the feed point, but at any position between the two central loops, and in this way can match the antenna to a wide range of input feed lines.

\section{COMPARATIVE ANALYSIS OF MEANDER AND HELIX ELECTRICAL DIPOLE ANTENNAS}

In this section, the shunt-matched spherical meander antenna described above is compared to a multiarm spherical helix antenna. As sketched in Fig. 5, the geometry for the later consists of top and bottom symmetric hemispheres composed of four helical arms with 1.5 turns in each [6, Section III]. Both antennas have the same radius $r_{0}=42.2 \mathrm{~mm}$ and wire diameter $2 r_{w}=2.6 \mathrm{~mm}$; both are assumed to be lossless. Both antennas radiate the $\mathrm{TM}_{10}$ spherical mode and yield $Q$ 's that are close to the bound $1.5 Q_{\text {LB }}$ predicted by Thal [4]. 
Fig. 6 plots the input impedance of the antennas versus frequency. The geometry of the meander antenna is adjusted to realize the resonance at nearly the same frequency as the helix antenna. The meander antenna delivers 71.8 ohms input resistance at the resonance, whereas the helix antenna yields $48.8 \mathrm{ohms}$. Despite the appreciable differences in the input impedance behavior, both antennas exhibit nearly the same reflection coefficient, when it is normalized to 75 and 50 ohms, respectively (Fig. 7). Consequently, the $Q$ factors are nearly the same as well (Tab. 2).

At this point, it is important to note that the choice of the radius of the minimum sphere $a$ significantly affects the ratio $Q / Q_{\mathrm{LB}}$. There are two approaches pursued in the literature with respect to spherical wire antennas. The first one, which appears to be followed in $[8,6]$, assumes the minimum sphere radius coincides with the antenna radius $a=r_{0}$, i.e. axes of the wires lie along the surface of the minimum sphere. Thus, half of a wire remains outside the minimum sphere. In the the second approach, the whole wire is enclosed in the minimum sphere, that is $a=r_{0}+r_{w}$ [7, 10]. The results of these two approaches are summarized in Tab. 2. It is observed that the first approach results in $Q / Q_{\mathrm{LB}}=1.54$ and $Q / Q_{\mathrm{LB}}=1.53$ for the meander and helix antennas, respectively. The later value of $Q / Q_{\mathrm{LB}}$ agrees with the result reported in [6]. The second approach yields $Q / Q_{\mathrm{LB}}=1.68$ and $Q / Q_{\mathrm{LB}}=1.67$, respectively, which is still close to the Thal bound $Q / Q_{\mathrm{LB}}=1.5$ for an electrically small electric dipole antenna, but appreciably higher as compared to the first approach.

Tab. 2. Characteristics of the meander and helix antenna.

\begin{tabular}{lccccccccc}
\hline \hline & & \multicolumn{4}{c}{$a=r_{0}=42.2 \mathrm{~mm}$} & \multicolumn{3}{c}{$a=r_{0}+r_{w}=43.5 \mathrm{~mm}$} \\
& $f_{0}, \mathrm{MHz}$ & $R_{0}, \Omega$ & $Q$ & $k a$ & $Q_{\mathrm{LB}}$ & $Q / Q_{\mathrm{LB}}$ & $k a$ & $Q_{\mathrm{LB}}$ & $Q / Q_{\mathrm{LB}}$ \\
\hline meander & 300.4 & 71.8 & 88.0 & 0.266 & 57.1 & 1.54 & 0.274 & 52.3 & 1.68 \\
helix & 300.6 & 48.8 & 87.2 & 0.266 & 57.0 & 1.53 & 0.274 & 52.2 & 1.67 \\
\hline
\end{tabular}

Since the meander and helix antennas are electrically small, the $\mathrm{TM}_{10}$ spherical mode dominates in their radiation spectrum, and their radiation patterns closely reproduce that of an elementary electric dipole (Fig. 8). However, their cross-polarization characteristics are quite different. (Here, the the cross-polarization is understood according to the Ludwig's second definition [11].) For the meander antenna, the TE 11 spherical mode is responsible for the crosspolarization, whereas for the helix antenna, it is the $\mathrm{TE}_{20}$ mode. Consequently, the cross-polarization pattern of the helix antenna is omnidirectional (Fig. 8b), whereas the meander antenna radiates the cross-polar component only in the YZ-plane (Fig. 8a).

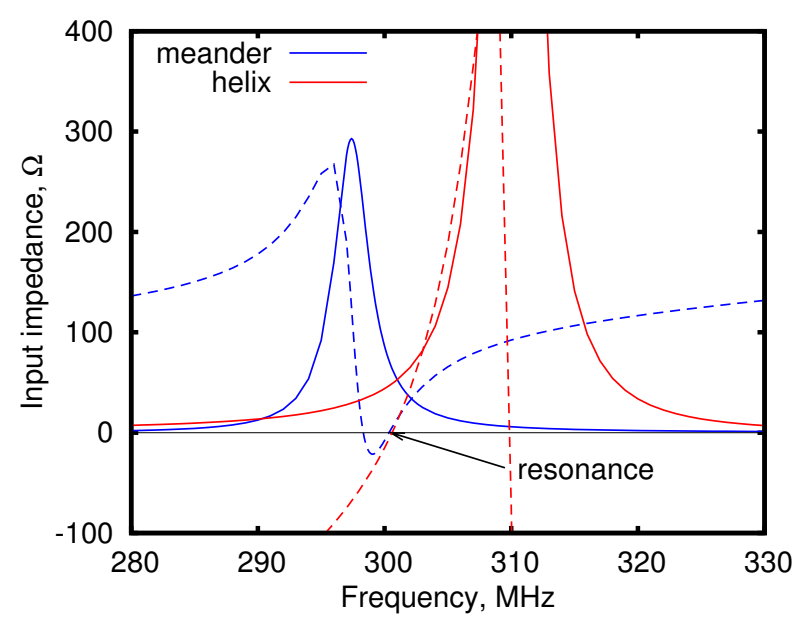

Fig. 6. Input impedance of the meander and helix antennas.

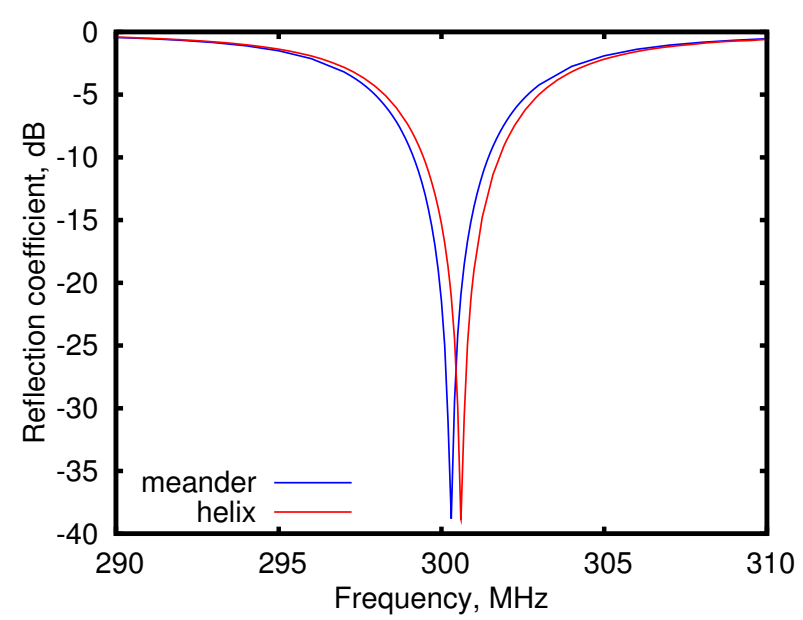

Fig. 7. Reflection coefficient of the meander and helix antennas with respect to 75 and $50 \mathrm{ohms}$, respectively. 


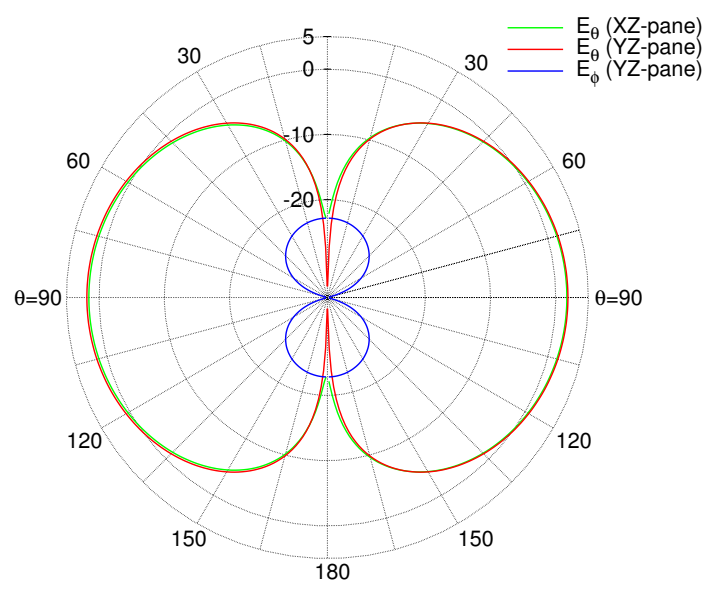

(a) spherical meander antenna

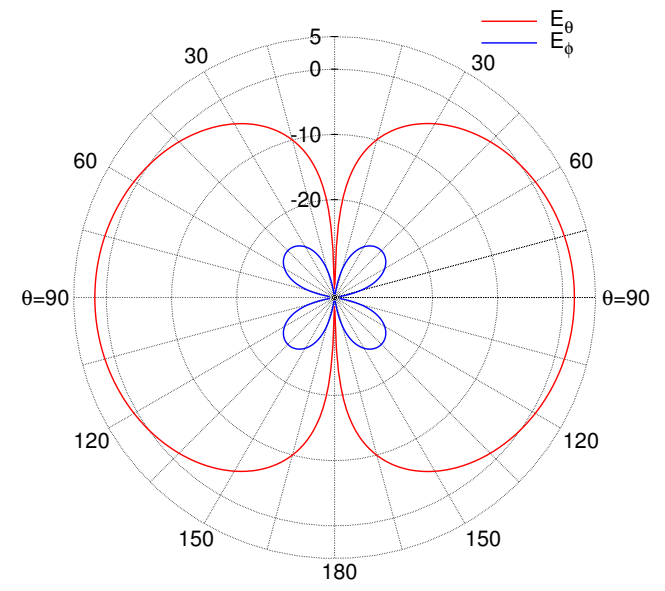

(b) spherical helix antenna

Fig. 8. Radiation patterns of the electrically small electric dipole antennas (vertical plane, in dBi).

\section{CONCLUSION}

Spherical meander antenna is presented and numerically investigated. Due to closely spaced horizontal loop-shaped meander sections the antenna is able to operate in the electrically small regime. It is self-resonant and radiates the $\mathrm{TM}_{10}$ spherical mode, and thus, akin to the multiarm spherical helix antenna [8]. Results of the numerical investigations reveal very similar performance of both antennas, which differ mainly in the distribution of the horizontally polarized (cross polar) component. It is also shown how important it is to define clearly the radius of the minimum sphere, since this has significant effect on the $Q / Q_{\mathrm{LB}}$ ratio of an electrically small antenna.

\section{ACKNOWLEDGMENT}

This work is supported by the Danish Research Council for Technology and Production Sciences within the TopAnt project (http://www.topant.dtu.dk).

\section{REFERENCES}

[1] H. A. Wheeler, "Fundamental limitations of small antennas," Proc. IRE, vol. 35, no. 12, pp. 1479-1484, 1947.

[2] L. J. Chu, "Physical limitations of omni-directional antennas," J. Appl. Phys., vol. 19, no. 12, pp. 1163-1175, 1948.

[3] J. S. McLean, "A re-examination of the fundamental limits on the radiation Q of electrically small antennas," IEEE Trans. Antennas Propagat., vol. 44, no. 5, pp. 672-676, 1996.

[4] H. L. Thal, "New radiation Q limits for spherical wire antennas," IEEE Trans. Antennas Propagat., vol. 54, no. 10, pp. 2757-2763, 2006.

[5] S. R. Best, "The radiation properties of electrically small folded spherical helix antennas," IEEE Trans. Antennas Propagat., vol. 52, no. 4, pp. 953-960, 2004.

[6] _ "A low Q electrically small magnetic (TE mode) dipole," IEEE Antennas Wireless Propagat. Lett., vol. 8, pp. 572-575, 2009.

[7] O. S. Kim, "Low-Q electrically small spherical magnetic dipole antennas," IEEE Trans. Antennas Propagat., in press.

[8] S. R. Best, "Low Q electrically small linear and elliptical polarized spherical dipole antennas," IEEE Trans. Antennas Propagat., vol. 53, no. 3, pp. 1047-1053, March 2005.

[9] E. Jørgensen, O. S. Kim, P. Meincke, and O. Breinbjerg, "Higher order hierarchical legendre basis functions in integral equation formulations applied to complex electromagnetic problems," in Proc. IEEE Antennas and Propagation Soc. Int. Symp., vol. 3A, Washington DC, July 2005, pp. 64-67.

[10] O. S. Kim and O. Breinbjerg, "Electrically small magnetic dipole antennas with radiation quality factor Q approaching the Chu lower bound," submitted to IEEE Trans. Antennas Propagat., 2009.

[11] A. Ludwig, "The definition of cross polarization," IEEE Trans. Antennas and Propagat., vol. AP-21, no. 1, pp. 116-119, 1973. 